\title{
Research Paper: Relationship Between Social, Economic and Cultural Factors and Women's Tendency Toward Crystal Methamphetamine or Opium Use
}

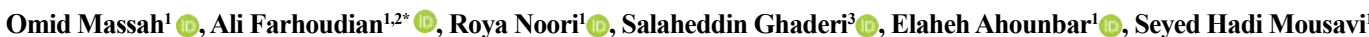

1. Substance Abuse and Dependence Research Center, University of Social Welfare and Rehabilitation Sciences, Tehran, Iran.

2. Department of Psychiatry, School of Medicine, Tehran University of Medical Sciences, Tehran, Iran.

3. Department of Sociology, Faculty of Literature and Humanities, Kharazmi University, Tehran, Iran.

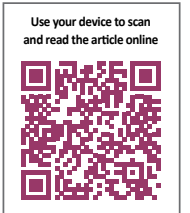

Citation: Massah O, Farhoudian A, Noori R, Ghaderi S, Ahounbar E, Mousavi SH. Relationship between Social, Economic and Cultural Factors and Women's Tendency toward Crystal Methamphetamine or Opium Use. Iranian Rehabilitation Journal. 2018; 16(3):247-254. http://dx.doi.org/10.32598/irj.16.3.247

http://dx.doi.org/10.32598/irj.16.3.247

\section{(c) (1) (8)}

Funding: See Page 253

Article info:

Received: 13 Mar 2018

Accepted: 05 Jul 2018

Available Online: 01 Sep 2018

\section{Keywords:}

Crystal meth, Opium,

Methamphetamine, Tendency,

Illicit drug use, Women, Iran

\section{ABSTRACT}

Objectives: High prevalence of stimulants use -especially crystalline methamphetamine (crystal meth)-, which required extensive medical and rehabilitation interventions is a major problem in Iran's health care system. Main objective of the current study was to compare social, economic and cultural factors associated with female's tendency toward use of two main types of drugs including opium and crystal methamphetamine.

Methods: The present cross-sectional and comparative study was performed on female opium and Methamphetamine (MA) dependents of Tehran in 2015. 136 women (82 crystal meth consumers and 54 opium consumers) were selected by simple random sampling method whom filled a researcher-developed questionnaire. Data was analyzed by Pearson Correlation Coefficient and Chi-square test using SPSS software V. 19.

Results: There were significant differences between two groups in terms of marital status $(\mathrm{P}=0.012)$, the believe in better fitness with drug use $(\mathrm{P}=0.011)$, and the believe in improved working and studying efficacy $(\mathrm{P}=0.039)$.

Discussion: It seems that misconceptions of beneficial impact of crystal methamphetamine use on fitness and improved working and studying efficacy could be recognized as a prominent factor for women's tendency toward crystal methamphetamine use. Also, being single and avoiding a stable marital life was a strong factor associated with such tendency. This was whilst opium use was more prevalent among married women, and especially those influenced by their addicted spouse.

\section{* Corresponding Author:}




\section{Highlights}

- Misconceptions of beneficial impact of crystal meth on fitness and improved working efficacy is the main reason for women to use crystal meth in Iran.

\section{Plain Language Summary}

Female's addiction is a threat to the health of the society. Substance abuse has recently increased among females in Iran, and tendency toward stimulants use including crystal methamphetamine (glass) has been more than ever. The main motive for conducting the present study was the increased tendency toward crystal methamphetamine (glass) abuse among the Iranian women. The results of the current study indicate that Iranian females misinterpret the effects of glass abuse on fitness and improved occupational and educational functioning. Furthermore, glass abuse is more prevalent among single females.

\section{Introduction}

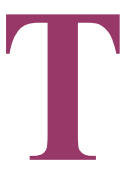

endency toward substance use is among major topics to be investigated in the field of addiction sciences. Prior researches have documented various assumptions about the etiology of drug abuse, but none of those could solely determine reasons to individual's tendency toward drug use. In most cases, this is typically a complex problem; but some specific factors play more highlighted roles in different socio-cultural situations, as it differs from person to person $[1,2]$. In fact, substance dependence is a bio-psycho-social problem. In other words, biological aspects like hormone changes and shifts in neurotransmitters, social aspects including poverty, unemployment, addiction in other family members and immigration, and psychological aspects such as feelings of inferiority and insecurity, stressful life events like war, joining military service and a longdistance family; all together evolve basis of tendency toward drug abuse [3].

Most people find illicit drug use as a rather masculine phenomena and that women are much less likely to involve drugs and addiction. Results of a national epidemiological survey on the general population regarding substance use and health consequences of it which was conducted as direct interviews in the emergency wards of hospitals of Iran, approved that $2 \%$ of women used opium and $0.05 \%$ of them were depended on opium and its derivatives [4].

There are growing evidence for an increasing trend of addiction among females during the past 20 years, in which ratio of women who use illicit drugs versus total population of drug abusers was increased from almost $4 \%$ in 1998 to $9 \%$ in 2013 . That means the proportion of men to women in total drug abuse population is 10 to 1 ; It is necessary to mention that this ratio is lower for some substances; for instance; the ratio reaches 4-6 to 1 in case of Amphetamine Type Stimulants (ATS), indicating a closer difference between the two genders [5-8]. According to the latest national survey on drug abuse in Iran (2015), about 3.3\% of females aged 15 to 64 years reported histories of at least one type of narcotics and/or stimulants use during lifetime [9].

A serious threat which arises in this domain is a change in the pattern of illicit drugs use from more natural substances (narcotics) to synthetic and chemical ones that has been plaguing our country over the past few years; as crystalline methamphetamine (crystal meth) use has been dramatically increased among the youth and females during the past decade [10]. There have been numerous studies to suggest increased use of Methamphetamines (MA) among patients referred to the emergency rooms of psychiatric centers [11], the young generation [12], patients under opiate abuse treatment [13], and injection drug users who consume shared syringe [14]. This has also been explored in estimation of alcohol and illicit drug use rates in 2013 and the whole country's consumption of crystal meth was reported 590 per 100,000 people [8]. This increase has also been reported in women $[15,16]$.

Previous studies have shown that enhancing harm and tension caused by social changes as well as intensified and modern roles of women could be a potential element in increased tendency to substance use among females. Practicing illicit drug use among women challenges their roles as a mother and wife in the society [17].

A number of authors in literature has discussed that female's drug dependence not only affects their own 
health, but also harms their children and other young family members. Drug abuse particularly causes various mental and physical disorders in their fetus $[18,19]$. As has been previously reported in the literature, compared to men, the biological characteristics of females, psychologically and physically makes them more susceptible to the negative effects of alcohol, tobacco, and other types of drugs, as women are more likely to develop complications associated with drug and alcohol abuse (i.e. alcohol-induced liver disease) much earlier than men [20].

Considering the important role of women in the society, vulnerabilities that threaten female's physical and psychological health are serious challenges of our country and must be among research necessities of the health system. On the other hand, the rate of crystal meth abuse was dramatically raised consequence to provision of amphetamine type stimulants in the market, due to its pseudo-attractive features. Better identification of factors involving tendency toward abusing cutting-edge substances, may lead to designing more appropriate preventive and therapeutic services. Main objective of the current study was to investigate and compare causes of the tendency toward opium and crystal meth among females, in respect of social, economic and cultural factors. With this aim in mind, in this paper we present whether other factors impact the increasing use of methamphetamine, or is it only the same relatively recognized reasons to tendency toward opium abuse?

\section{Methods}

The present cross-sectional and comparative study was part of a large survey and performed on female opium and MA users of Tehran in 2015. We performed comparison in respect of demographic data, as well as social, economic and cultural indicators.

\section{Participants}

The statistical population of the present study consisted of female drug users who referred to 1. Congress 60 (a self-help group NGO); 2 . Outpatient clinics for substance use treatment; 3. Residential treatment centers; 4. Harmreduction centers Drop-in Center (DIC); 5. Imprisoned women; 6 . Those under clause 16 (the law that obliges drug dependents to undergo compulsory treatment) who have been under treatment for less than one month, and 7. Female drug abusers under no treatment of Tehran.

A sample size of 125 individuals was required, which ultimately 140 participants were selected, due to dispersion and variability in independent variables and possibility of subjects' loss. Inclusion criteria were as follows: opium or methamphetamine use and being diagnosed as drug dependent based on DSM-V. Exclusion criteria were follows: being a poly drug user and having psychosis.

The participants (140 persons) were divided into seven mentioned sub-groups and twenty people were evenly selected from each of the groups (congress 60, outpatient clinics for substance use treatment, residential treatment centers, harm-reduction centers, imprisoned women and those under clause 16) through simple random sampling method. Eventually, females who were not under any treatment programs (20 samples) were selected by snowball sampling method [21]. After completion of data gathering, 136 questionnaires were recognized eligible to enroll into statistical analysis process.

\section{Study tools}

A researcher-made data gathering form structured on the basis of subjectivisms demonstrated in the prior pilot and qualitative studies was applied to collect survey data. The qualitative section of the study included a series of in-depth interviews with experts, therapists and policy makers in the field of prevention, treatment and harmreduction of addiction. The research tool structure was designed according to the results of this part of the study.

\section{Data analysis}

After finalizing design of the questionnaire, a pilot study was carried out to evaluate the tool in which Cronbach's alpha of 0.726 was obtained. Data were analyzed by Pearson Correlation Coefficient and Chi-square test using SPSS software V. 19

\section{Results}

Of all 136 study participant, 54 were opium users and 82 were users of crystal methamphetamine. In other words, $39.7 \%$ and $60.3 \%$ of the samples were dependent to opium and crystal methamphetamine, respectively. The mean age of opium users was 36 years, median was 35 years; minimum 18 and maximum 60 years with SD of 10. Mean age of crystal methamphetamine users was 31 years, median of 30 years; minimum 18 and maximum 55 years with SD of 7 years. There was a significant difference between the two groups with respect to their age $(\mathrm{P}<0.05)$. It is necessary to mention that the group of opium users consumed opium only and MA users group, solely consumed crystal methamphetamine. 
Table 1. Marital status of two groups of study (54 female opium users and 82 female crystal methamphetamine users)

\begin{tabular}{|c|c|c|c|c|}
\hline Marital Status & Statistical Indicator & Opium & Crystal Methamphetamine & Total \\
\hline \multirow[b]{2}{*}{ Single } & Number & 10 & 31 & 41 \\
\hline & Percentage & 18.5 & 37.8 & 30.1 \\
\hline \multirow{2}{*}{ Married } & Number & 16 & 13 & 29 \\
\hline & Percentage & 29.6 & 15.5 & 21.3 \\
\hline \multirow{2}{*}{ Seperated } & Number & 10 & 11 & 21 \\
\hline & Percentage & 18.5 & 13.4 & 15.4 \\
\hline \multirow{2}{*}{ Divorced } & Number & 10 & 15 & 25 \\
\hline & Percentage & 18.5 & 18.3 & 18.4 \\
\hline \multirow{2}{*}{ Widowed } & Number & 8 & 5 & 13 \\
\hline & Percentage & 14.8 & 6.1 & 9.6 \\
\hline \multirow{2}{*}{ Temporary marriages } & Number & 0 & 7 & 7 \\
\hline & Percentage & 0.0 & 8.5 & 5.1 \\
\hline \multirow{2}{*}{ Total } & Number & 54 & 82 & 136 \\
\hline & Percentage & 100.0 & 100.0 & 100.0 \\
\hline
\end{tabular}

The study findings suggested no significant difference between the groups in respect of their level of education, which means that education has no significant impact on tendency toward abusing a specific drug type $(\mathrm{P}=0.664)$. Data indicated a significant difference between the two groups in terms of marital status $(\mathrm{P}=0.012)$. According to our findings, rate of crystal methamphetamine use was higher among single women or those who attempted temporary marriages, this was whilst opium use was significantly higher than crystal methamphetamine use among married women who were in a stable marital relationship (Table 1).

Findings demonstrated no statistically significant difference between the two groups of study, in respect of their ethnicity $(\mathrm{P}=0.822)$, family monthly income $(\mathrm{P}=0.119)$, type of occupation in the past year $(\mathrm{P}=0.524)$, parent's level of education ( $\mathrm{P}=0.632)$, parent's occupation $(\mathrm{P}=0.588)$, and housing status $(\mathrm{P}=0.464)$. It could be concluded that most of social, economic and cultural indicators didn't have any effect on using opium or crystal meth among females living in Tehran.

There was no significant difference between opium users and MA users in belief in regard to "more beauty and attractiveness because of drug use" $(\mathrm{P}=0.077)$. Al- though it is considerable the obtained probability value of comparing this variable was almost close to the significance level. Two groups' assumptions in regards to "drugs causing better fitness" were significantly different $(\mathrm{P}=0.011)$ in which crystal methamphetamine users believed they could reach a better body feature and fitness, by consuming this stimulant (Table 2).

In terms of tendency toward opium or MA because of "masculine imitation interest", there was no significant difference between the two groups $(\mathrm{P}=0.335)$. Also, tendency toward opium or crystal methamphetamine use due to "achieve self-identity, social gesture and being up to date" $(\mathrm{P}=0.318)$ and "sexual pleasure" $(\mathrm{P}=0.318)$ were not significantly different among females in Tehran. Tendency toward drug use because of "improved work/ education efficiency or creation of works of art" was significantly different between opium dependents and MA dependents $(\mathrm{P}=0.039)$ as MA users believed that they would have better results with drug use (Table 3 ).

\section{Discussion}

The aim of this study was to compare social, economic and cultural factors associated with tendency toward opi- 
Table 2. Results of 54 opium users and 82 crystal methamphetamine users in respect of improved fitness by drug use in Tehran

\begin{tabular}{|c|c|c|c|c|}
\hline Improved Fitness & Statistical Indicator & Opium & Crystal Methamphetamine & Total \\
\hline \multirow{2}{*}{ Completely agree } & Number & 8 & 32 & 40 \\
\hline & Percentage & 14.82 & 39.1 & 29.4 \\
\hline \multirow{2}{*}{ Agree } & Number & 9 & 14 & 23 \\
\hline & Percentage & 16.66 & 17.1 & 16.9 \\
\hline \multirow{2}{*}{ Unbiased } & Number & 17 & 12 & 29 \\
\hline & Percentage & 31.48 & 14.6 & 21.3 \\
\hline \multirow{2}{*}{ Disagree } & Number & 8 & 14 & 22 \\
\hline & Percentage & 14.82 & 17.1 & 16.2 \\
\hline \multirow{2}{*}{ Completely disagree } & Number & 12 & 10 & 22 \\
\hline & Percentage & 22.22 & 12.1 & 16.2 \\
\hline \multirow{2}{*}{ Total } & Number & 54 & 82 & 136 \\
\hline & Percentage & 100.0 & 100.0 & 100.0 \\
\hline
\end{tabular}

Ilranian Rehabilitation Journal

um or crystal meth use among women in Tehran. From the short review above, a key finding emerge that one of our main criteria for sample selection process was solely using a single type of drug, in order to reach accurate data regarding participant's characteristics of the same drug.

An important finding was understanding that frequency of using solely crystal meth was higher, compared to using solely opium. It shall be pointed out that of all participants, 82 subjects were abusers of crystal metham- phetamine and 54 abused opium, which reflects a high concern regarding growing crystal methamphetamine abuse among women. However, the general prevalence of opium is estimated higher than crystal meth, considering opium addicted females who occasionally use crystal methamphetamine. Seems like patterns of drug use among statistical population of this study is different than the overall pattern of drug use in the country which is highly influenced by the types of drug used by men; therefore, this issue requires special attention. Based

Table 3. Results of two groups in respect of "improved work/education efficiencyor creation of works of art" by drug use in Tehran

\begin{tabular}{|c|c|c|c|c|}
\hline $\begin{array}{l}\text { Improved Work/Education Efficiency and } \\
\text { Creation of Works of Art by Drug Use }\end{array}$ & Statistical Indicator & Opium & Crystal Methamphetamine & Total \\
\hline \multirow{2}{*}{ Completely agree } & Number & 12 & 34 & 46 \\
\hline & Percentage & 22.2 & 41.4 & 33.8 \\
\hline \multirow{2}{*}{ Agree } & Number & 18 & 25 & 43 \\
\hline & Percentage & 33.4 & 30.5 & 31.6 \\
\hline \multirow{2}{*}{ Unbiased } & Number & 6 & 7 & 13 \\
\hline & Percentage & 11.1 & 8.5 & 9.6 \\
\hline \multirow{2}{*}{ Disagree } & Number & 12 & 8 & 20 \\
\hline & Percentage & 22.2 & 9.8 & 14.7 \\
\hline \multirow{2}{*}{ Completely disagree } & Number & 6 & 8 & 14 \\
\hline & Percentage & 11.1 & 9.8 & 10.3 \\
\hline \multirow{2}{*}{ Total } & Number & 54 & 82 & 136 \\
\hline & Percentage & 100.0 & 100.0 & 100.0 \\
\hline
\end{tabular}


on most epidemiologic studies in the last two decades, opium and alcohol have been the most prevalent drugs among females, and in last decade crystal methamphetamine consumption has grown dramatically.

A review study by Rahimi Movaghar in 2004 showed that opium was recognized as the most commonly used drug among women $[4,22]$. Studies conducted during late 2000's about lifetime used drugs by women suggested the following rates of abuse: alcohol (4.7\%), opium $(1.6 \%)$, crystal methamphetamine $(1.2 \%)$, and hashish $(1.1 \%)$, another study demonstrated in the following year also suggested that alcohol (1.3\%) and crystal methamphetamine (1\%) were respectively the most prevalent substances used by females $[23,24]$. The main point to the current study was crystal methamphetamine as the current most commonly abused drug among study population. A similar pattern of results was obtained in the study of Noori et al., in 2012, in which they showed most females with drug use disorders (59\%), were dependent on crystal methamphetamine as their top abused substance, regardless of their concurrent abuse of narcotics and stimulants [23].

Mean age of females using opium and crystal methamphetamine were 36 and 31 years, respectively. Obtained data from the current research were significantly higher than reports of previous studies. For instance, Noori et al. have documented 30 years for the mean age of females using opium and 27.5 years for female crystal methamphetamine users; they have also mentioned that almost $90 \%$ of this population aged under 35 years [24]. In line with that, other studies also reported a lower mean age compared to the current study $[25,26]$.

Such difference could be explained by different sample (statistical) population that varied between the studies. Most participants of the present study were under some kind of treatment (voluntarily or compulsory) and it is only normal that people are usually referred to treatment centers after few years of struggling with drug use disorders and naturally at higher ages; on the other hand, other studies with the target of determining drug use prevalence among women accessed a larger number of women under no treatment and of younger ages.

Findings of the current study suggested no significant correlation between the two groups in terms of level of education and tendency toward a specific type of drug. This finding was contrary to the results of Noori et al., wherein such difference was found significant [24]. This study, has explored variables relevant to social, economic and cultural characteristics of the subjects and found no significant association between most of these variables and tendency toward any type of drugs in particular. As per these findings, level of income, ethnicity, occupation, level of education and type of housing were not significantly different between the two groups of study; which is contrary to the results obtained by Khademian et al. (2008) in which reported a significant relationship between socio-economic status of women and their preferred type of abused drug. They have explained that women with lower socio-economic status have been using opium, hashish (cannabis) and illegal methadone [27]

We speculate that this might be due to difference in the price of crystal methamphetamine at the time of conducting the two studies. It is important to note that, crystal methamphetamine used to be imported from other countries back then and the price was much higher, whilst the market for this substance is changed at the present time and it is distributed at a very cheaper cost.

A thought-provoking finding was the significant relationship between marital status of the subjects and tendency toward consuming a certain type of drug. As the rate of crystal methamphetamine use was significantly higher among women who attempted temporary marriages and the single ones; whilst a higher rate of opium abuse was seen in the married women. This is consistent with what has been found in a previous investigation conducted in 2010, that explored the status of stimulants abuse in Tehran and realized half of the female stimulant users were single [24].

Finding showed no significant difference between two study groups in belief in regard to more beauty and attractiveness because of drug use; but a significant difference was seen between the two groups in terms of improved fitness by using drug; as the group of crystal methamphetamine users mainly believed that using this substance leads to weight loss and better body figure in them. In addition, while the difference between two groups was not significant in their assumptions in regards to higher beauty and attractiveness, still this variable was scored much higher among crystal methamphetamine users group.

A similar finding was reached by Noori et al., whom suggested that more than half of individuals initially attempted crystal methamphetamine abuse in aim of getting lean [24]. A further novel finding was that the group of females with crystal methamphetamine use, significantly believes that substance abuse enhances focus and improves working/studying efficacy or improves creating works of art. Of course, there are other 
differences in the personality characteristics of the two groups of opiates and stimulants users that should be investigated in women [28].

\section{Conclusion}

In summary, this study argued that numerous factors affect women's tendency toward drug use which most of them are involved in this phenomena without a statistically significant difference. However, some women tend to use crystal methamphetamine more than others, including single women, the ones who attempt temporary marriages and those with misconceptions of beneficial impact of using crystal methamphetamine on better fitness and improved working and studying efficacy.

The approach utilized suffers from the limitation that the research design and statistical analysis used in the current work, lacked the casual inference potency for the explored variables of study; therefore, it was not possible to specify casual and non-causal relationships. In other words, obtained significant relationships only reflect coexistence and correlation between the variables and we cannot certainly regard one as a direct cause of another.

Another limitation in this research involves the issue of inability to accurately control confounding variables, in which makes it impossible to attribute the relationship between the studied variables to the investigated independent variables and of course, besides the independent variable, numerous factors could have contributed to the formation of dependent variable that were missing our realization.

Ideally, these findings should be replicated in a study focused on each factor that found to be statistically significant with tendency to consuming a specific type of drug among this study groups; it is also needed to consider more expanded and accurate items and variables to be explored in the questionnaire.

The broad implication of the present research could be considering women's misconception regarding optimal use of opium to reduce complications and symptoms of physical diseases, as well as feeling of peacefulness after physical disputes and false believe in positive efficacy of crystal meth on improving work and studying efficacy and reaching body fitness, in the future educational and consulting planning extensively.

\section{Ethical Consideration}

\section{Compliance with ethical guidelines}

This article has been extracted from research project (801/93/10355/1) which was approved by ethics committee of University of Social Welfare and Rehabilitation Sciences.

\section{Funding}

This study was funded by research deputy of University of Social Welfare and Rehabilitation Sciences.

\section{Conflict of interest}

The authors have no conflict of interest.

\section{Acknowledgements}

The authors highly appreciate all participants in the study, also appreciate all colleagues from different treatment or harm reduction centers who helped us.

\section{References}

[1] Jessor R. A psychosocial perspective on adolescent substance use. In: Litt IF, editor. Adolescent Substance Abuse: Report on the Fourteenth Ross Roundtable. Columbus, $\mathrm{OH}$ : Ross Laboratories; 1983.

[2] Jessor R, Jessor S. Adolescence to young adulthood: A twelve-year prospective study of problem behavior and psychosocial development. In: Menard S, editor. Handbook of Longitudinal Research. Cambridge: Academic Press; 1984.

[3] Walters GD. The addiction concept: Working hypothesis or self-fulfilling prophesy? Upper Saddle River, New Jersey: Prentice Hall; 1999.

[4] Rahimi Movaghar A. [A review on the prevalence and the patterns of drug abuse in women in Iran (Persian)]. Social Welfare. 2004; 3(12):203-26.

[5] Sharifi V, Amin-Esmaeili M, Hajebi A, Motevalian A, Radgoodarzi R, Hefazi M. Twelve-month prevalence and correlates of psychiatric disorders in Iran: The Iranian Mental Health Survey, 2011. Archives of Iranian Medicine. 2015; 18(2):76-84. [PMID]

[6] Haghdoost AA, Jafari F, Tarjoman T, Meamarian N, Baneshi MR, Haji Maghsoudi S. [Estimating population size of drug and alcohol abusers in Iran 2012 (Persian)]. Tehran: Sepidbarg; 2012.

[7] Masoumeh AE, Afarin RM, Vandad S, Ahmad H, Reza R, Ramin M, et al. Epidemiology of illicit drug use disorders in Iran: prevalence, correlates, comorbidity and service utilization results from the Iranian Mental Health Survey. Addiction. 2016; 111(10):1836-47. [DOI:10.1111/add.13453] [PMID] 
[8] Nikfarjam A, Shokoohi M, Shahesmaeili A, Haghdoost AA, Baneshi MR, Haji-Maghsoudi S, et al. National population size estimation of illicit drug users through the network scale-up method in 2013 in Iran. International Journal of Drug Policy. 2016; 31:147-52. [DOI:10.1016/j.drugpo.2016.01.013] [PMID]

[9] Roshanpajouh M. House hold national survey on illicit drug use in Iran 2015. National Report. Tehran: Welfare Organization of Iran; 2017.

[10] United Nations Office on Drugs and Crime. World drug report 2015. New York: United Nations Publications; 2015.

[11] Zarghami M. Methamphetamine has changed the profile of patients utilizing psychiatric emergency services in Iran. Iranian Journal of Psychiatry and Behavioral Sciences. 2011; 5(1):1-5. [PMID] [PMCID]

[12] Momtazi S, Rawson RA. Substance abuse among Iranian high school students. Current Opinion in Psychiatry. 2010; 23(3):221-6. [DOI:10.1097/YCO.0b013e328338630d] [PMID] [PMCID]

[13] Mokhber N, Afshari R, Farhoodi F. Evaluation of the suicide risk factors among methadone maintenance treatment of opiate dependent individuals: A six month assessment Open Journal of Psychiatry. 2012; 2(2):18477. [DOI:10.4236/ ojpsych.2012.22013]

[14] Rafiey H, Narenjiha H, Shirinbayan P, Noori R, Javadipour $\mathrm{M}$, Roshanpajouh $\mathrm{M}$, et al. Needle and syringe sharing among Iranian drug injectors. Harm Reduction Journal. 2009; 6(1):21. [DOI:10.1186/1477-7517-6-21] [PMID] [PMCID]

[15] Massah O, Moradi A. The Prevalence of methamphetamine dependence among Iranian Women in methadone maintenance therapy in Tehran, Iran. Iranian Journal of Psychiatry. 2018; 13(1):10-4. [PMID] [PMCID]

[16] Massah O, Shishehgar S. Methamphetamine dependence, psychological well-being, criminality and high risk sexual behaviors in female-only methadone services in Tehran and Karaj, Iran. Iranian Journal of Psychiatry and Behavioral Sciences. 2018; 12(2):e61859. [DOI:10.5812/ijpbs.61859]

[17] United Nations Development Fund for Women. Women and Drugs: From Hard Realities to Hard Solutions. Paper on Women, Gender and Drugs. New York: United Nations Development Fund for Women; 2008.

[18] Willis K, Rushforth C. The female criminal: An overview of women's drug use and offending behaviour. Trends \& Issues in Crime and Criminal Justice. 2003; 264:1-6.

[19] Kunst A, Giskes K, Mackenbach J. Socio-economic inequalities in smoking in the European Union. Applying an equity lens to tobacco control policies. Rotterdam: Erasmus Medical Center Rotterdam; 2004.

[20] National Institute on Alcohol Abuse and Alcoholism. Alcohol: A women's health issue. Bethesda: NIH Publication; 2003.

[21] Jalali R. [Qualitative research sampling (Persian)]. Journal of Qualitative Research in Health Sciences. 2013; 1(4):310-20.

[22] Yasemi M. [Prevalence of substance abuse in Iran (Persian)]. Tehran: Iran Drug Control Headquarters; 2002.

[23] Noori R. [The study of the status of women's residential centers for drug use treatment and identify the needs of women. Final report (Persian)]. Tehran: University of Social Welfare and Rehabilitation Sciences; 2013.
[24] Noori R, Rafiei H, Narenjiha H, Baghestani A, Kioomarsi A. [The trend of using stimulant drugs in Tehran (Persian)]. Tehran: Dariush Institute; 2011.

[25] Barati M, Ahmadpanah M, Soltanian A. Prevalence and factors associated with methamphetamine use among adult substance abusers. Journal of Research in Health Sciences. 2014; 14(3):221-6. [PMID]

[26] Hamdieh M, Borujerdi A, Motalebi N, Abbasinejad M, Asheri H, Motamedi A. The prevalence of cigarette smoking, alcohol consumption, psychostimulant and cannabinoid drugs abuse among 15 to 35 years old Tehranis. Iranian Journal of Psychiatry and Behavioral Sciences. 2010; 4(2):26-30.

[27] Khademian T, Ghanaatian Z. [A study on the effective social factor on the addiction of drug addicted women in rehabilitation and harm reduction of women in Tehran (Persian)] Journal of Social Sciences. 2009; 2(4):59-85.

[28] Karami Z, Pir-Khaefi AR, Kowsar-Nia A, Massah O, Farhoodian A. [Comparison of personality traits based on Temperament and Character Inventory (TCI) in opiate and stimulant abusers (Persian)]. Archives of Rehabilitation. 2014; 14(S1):83-90. 